\title{
LearnIt: A Serious Game to Support Study Methods in Engineering Education
}

\author{
Carlos Vaz de Carvalho \\ GILT \\ Instituto Superior de Engenharia do \\ Porto \\ Porto, Portugal \\ cmc@isep.ipp.pt
}

Pedro Bessa

GILT

Instituto Superior de Engenharia do Porto

Porto, Portugal

1150046@isep.ipp.pt

\author{
Ricardo Costa \\ GILT \\ Instituto Superior de Engenharia do \\ Porto \\ Porto, Portugal \\ 1150045@isep.ipp.pt
}

\author{
Ana Barata \\ GILT / DOG \\ Instituto Superior de Engenharia do \\ Porto \\ Porto, Portugal \\ abt@isep.ipp.pt
}

\author{
Alexandra Costa \\ $D O G$ \\ Instituto Superior de Engenharia do \\ Porto \\ Porto, Portugal \\ map@isep.ipp.pt
}

\begin{abstract}
The systematic application of study methods allows students to obtain better results in terms of knowledge acquisition and competences development. The successful application of those methods is directly related to the improvement of cognitive areas, such as memory, attention, and concentration in a simultaneously beneficial way. In the scope of the collaboration between a Student Support Center in a Higher Education Engineering Institution and an R\&D group in Educational Technologies, an application was designed to foster both vectors, the development of cognitive capabilities and the adoption of study methods. The application integrates a serious game and a repository of contextualized educational resources. This combination motivates students to adopt these tools more regularly. This article describes the developed application and the positive results of its use with a first group of students.
\end{abstract}

Keywords- Serious Games; Study Methods, Cognitive Development

\section{INTRODUCTION}

The literature indicates that study methods are not always directly focused on the curricula despite the impact they have on students' academic results and on the development of their skills. A general lack of work methodologies leads students to not be appropriately prepared for classes, which in turn causes them to fail or get low grades. As a consequence, students experience added stress and poor self-esteem issues [1-3].

The systematic application of study methods allows students to achieve better results both regarding knowledge acquisition and skills development [3]. Throughout elementary and secondary education, students still get by without thoroughly considering applying a study method, and are able to progress; however, as content matters and subjects' get more complex, it becomes increasingly important to structure a coherent study method. This is particularly true for higher education students as one of the identified problems of this target group is their inability to apply systematically organized study methods, which later results in an inability to manage time and academic difficulties, consequently leading to loss of interest in the program or subject area, or even to dissatisfaction with the university experience, and ultimately ending in academic failure [4]. This might derive from the students' unawareness of such methods, but it may also be a consequence of sparse development of some cognitive areas like memory, concentration, and attention. Therefore, it is important to provide students with tools that potentiate solutions for both these vectors, improving namely their cognitive abilities, self-regulation skills, self-efficacy, and resilience.

Within the collaboration between a Student Support Centre in a Higher Education Engineering Institution and an R\&D group in Educational Technologies, potential ways to foster the improvement of students' awareness regarding study methods, and their potential to improve knowledge acquisition, comprehension and focus were analyzed following previous studies as well as the authors' actual local experience. The adopted solution was the LearnIt game (initially named KnowIt), an application combining a serious game approach and a contextualized repository of learning resources specifically directed to study methods and to the cognitive development areas. The basic justification for the selected approach was that well-designed serious games take advantage of their immersive and motivational nature to focus the attention of the player into specific skill and competence development objectives. This allows an effective and efficient process to take place.

This article describes the design and development of LearnIt and presents the positive results obtained with a first cohort of engineering students.

\section{BRAIN TRAINING GAMES}

Abt defines a game as "an activity between two or more decision makers who seek to achieve their goals in a limiting context" [5]. Salem and Zimmerman extend this definition by presenting games as "[...] systems in which players participate in an artificial conflict, defined by rules, the result of which is quantifiable" [6]. Games are, hence, excellent personal development tools as they force the player to solve problems, to prioritize, to collaborate, etc [7]. As such, playing games develops a set of interrelated cognitive areas. On top, games are also extremely effective in increasing students' motivation [8]. Serious games exploit this immersive and motivational nature of games to focus the player on a specific "serious" objective. Therefore, serious games are designed for a primary purpose other than pure entertainment [9]. This serious objective can be linked to defence, education, scientific exploration, health care, emergency management, city planning, engineering, and 
politics [10] even if Abt originally coined the term thinking solely on educational aspects [5].

Wattanasoontorn et al. mentioned that any game must have four components: rules or gameplay, interactivity, challenge and an explicit goal - entertainment. A Serious Game has these four components plus an additional - the implicit goal. This objective includes aspects such as physical improvement, competence development, knowledge acquisition or getting experience [11]. This is the case, for instance, of serious games created for the development of professional engineering skills and competences [12].

In the design of any game, serious or not, the concept of Flow presented by Csikszentmihalyi should guide the ideation process [13]. Csikszentmihalyi concluded that the relation between the individual skills and the difficulty of the tasks results in different cognitive and emotional states: when the difficulty of the tasks is higher than the user's abilities, he/she becomes anxious. When the opposite occurs, the user is bored. In situations where the difficulty and skills are well matched, the person gets in flow, which means that he/she is fully immersed in the experience. In fact, Baron proposes that, during the state of flow, people often experience [14]:

- A greater concentration on the task,

- A feeling that they are in control of the situation,

- Changes in the subjective perception of time,

- A feeling that the practice of the task is the only justification needed to continue to do it.

Csikszentmihalyi presented four aspects that drive the balance between skills and challenges, to increase the likelihood the user enters in a state of Flow [13].

- Having goals contracts and enforceable rules,

- Requiring actions to accomplish goals that are consistent with the person's abilities,

- $\quad$ Providing clear feedback and presenting frequent performance and objective achievement reporting,

- Decreasing the distraction of external means promoting an easier concentration.

For a serious game it is, therefore, extremely important to try to induce and maintain the state of flow in all players. Only then it would be possible to keep the player focused on the serious objective.

For this study, the focus was on the use of serious games specifically dedicated to cognitive function improvement also known as "Brain Training" games (also Cognitive Games or Cognitive Training Games). The main principle behind these games is that cognitive functions can be improved if "exercised" routinely [15]. This is a topic under debate especially for the unsubstantiated claims that some companies developing this type of games produced for marketing purposes [16]. But a meta-research showed that, in most cases, there has been, in fact, an improvement of the targeted cognitive functions [17]. And several other studies report positive results in the use of these games for cognitive development particularly in situations where some form of disability is present [18-21]. Although this was not the target group for this project, the number of successful cases reported enough data to consider that these games could also be used for the purpose of this study.

A set of existing games has been selected for analysis based on the following aspects:

- Proven scientific background of the games through an existing connection to a research group of scientists or psychologists;

- Proven results through extended database of users;

- Analysis by the psychologists that were involved in the LearnIt team.

This is the final set of games that was considered for an initial analysis:

- Brain Age is a series of video games initially launched in 2006 on the Nintendo DS, a gaming console. It was one of the earlier examples of Brain Training games to be popular with a large audience [22]. They were based on the book Train Your Brain: 60 Days to a Better Brain, written by neuroscientist Ryuta Kawashima [23]. The application was mainly composed of mini-games that train cognitive skills and included a player profile with scores for each addressed domain. It also includes a character (a polygonal head that it is a friendly representation of Dr. Kawashima himself) that constantly interacts with the user. In addition to explaining the game operation, this character makes several comments about the importance of exercising the brain, describes the part of the brain that is being exercised, presents the scores that the player is getting, provides suggestions of games and activities, describes facts about the brain function and how to keep in shape, etc. These interactions with the character are a good motivator and also contribute to a relaxed and informal game atmosphere. The game also uses the built-in console microphone to allow the user to interact with the mini-games. Finally, the game also includes activities that are classified as memory aids, but not games, and as such, do not affect the player profile. For instance, Dr. Kawashima's character can question the player about his/her day, such as "did you eat today?" Or "what you saw on television?". After some time, the character may again ask the user what he did that day. The game compares both answers and tells the user if he/she remembered correctly what happened [22].

- Lumosity is an online platform with a set of games addressing cognitive areas like memory, attention, cognitive flexibility, processing speed and ability to solve problems. The company responsible for the product, Lumos Labs, works with a team of over 100 researchers from around the world who collaborate with the game designers in the development of games. After signing up, the user is asked to complete 3 mini-games of different categories in order to have an initial assessment of his/her abilities. After this the player can either select an individual game or follow what the game calls "workout plan" and solve games in several different categories chosen by the program itself. A user profile is also provided with a history of user scores and other considerations about Lumosity practice (total games played, more categories of trained cognitive skills, etc.). The player can also get a comparison of his/her scores with other players of the same age, genre, 
professional or academic background, etc. Unfortunately, only a small subset of games is free so the user is subject to a monthly fee to unlock access to all the program features [24].

- Peak is a game for mobile devices, Android and iOS, developed in conjunction with a team of two experts in the neuroscience area. Similar to Lumosity, it contains mini-games designed to train cognitive skills. As a differentiating feature it offers Advanced Training modules that developers describe as intensive programs that train a specific cognitive skill [25]. It also provides the concept of a coach that will select specific exercises according to the previous track of results, namely on the areas that were identified as needing further development.
- BrainGymmer, again like Lumosity, is an online platform with a set of mini-games to develop cognitive skills. However, it must be used in a web browser, and it does not provide installable versions for desktop or mobile. The game was developed together with neuroscientists from five renowned universities [26].

- Fit Brains is yet another online platform with mini-games in order to develop cognitive skills. As the main differentiating factor, it claims to be the only service which includes emotional intelligence training, that is, the ability to understand and manage our emotions and those of others [27], although right now this has been supported by some of the other platforms.

Table 1 next provides a comparative overview of the main features of these games

Table 1 - Brain Training games comparison

\begin{tabular}{|c|c|c|c|c|c|c|}
\hline Game & Platform & Free version & Paid version & $\begin{array}{c}\text { Playable } \\
\text { offline }\end{array}$ & $\begin{array}{c}\text { Playable } \\
\text { Online }\end{array}$ & $\begin{array}{c}\text { Player } \\
\text { Profile }\end{array}$ \\
\hline Brain Age & Nintendo DS & No & Yes (license) & Yes & No & Yes \\
\hline Lumosity & $\begin{array}{c}\text { Android, iOS, web } \\
\text { browsers }\end{array}$ & $\begin{array}{c}\text { Yes (limited } \\
\text { functions) }\end{array}$ & $\begin{array}{c}\text { Yes } \\
\text { (subscription) }\end{array}$ & Yes & Yes & Yes \\
\hline Peak & Android, iOS & $\begin{array}{c}\text { Yes (limited } \\
\text { functions) }\end{array}$ & $\begin{array}{c}\text { Yes } \\
\text { (subscription) }\end{array}$ & Yes & Yes & Yes \\
\hline Brain Gymmer & Web browsers & $\begin{array}{c}\text { Yes (limited } \\
\text { functions) }\end{array}$ & Yes (license) & No & Yes & Yes \\
\hline Fit Brains & $\begin{array}{c}\text { Android, iOS, web } \\
\text { browsers }\end{array}$ & $\begin{array}{c}\text { Yes (limited } \\
\text { functions) }\end{array}$ & $\begin{array}{c}\text { Yes } \\
\text { (subscription) }\end{array}$ & Yes & Yes & Yes \\
\hline
\end{tabular}

Although the quality of the games was undoubtable and the concept of each individual mini-game was solidly established and connected to a specific cognitive domain, it was decided they would not fit the LearnIt objectives for the following reasons:

- They were not customisable to the specific purposes of Higher Education students;

- They did not use a metaphor that was adequate to those students;

- It was not possible to connect the games to the existing repository of learning contents;

\section{LEARNIT DESIGN}

Following the analysis of the existing games, and considering the objectives of the project, the team of psychologists involved in the LearnIt project presented the following set of predefined requirements:

- The cognitive areas to be addressed were: memory, verbal reasoning, numerical reasoning, abstract reasoning, focus and attention and emotions;

- The application should take the form of a collection of mini-games, since this is the most usual approach that users expect;

- These mini-games should be appropriate for short sessions, typical of casual games, so that they can be played in relaxed user moments;

- It should be clear which cognitive competence each mini-game aims to improve (although it is assumed that there is always some interrelation with other cognitive functions). For each cognitive area three games were to be developed;

- The user profile with scores is a useful feature that can contribute to widen the user's motivation;

- The application should run on the most popular platforms in mobile devices;

- A version compatible with personal computers should also be produced so that the user is provided with more options;

- The application should connect contextually to learning resources related to the cognitive functions and to the appropriate study methods;

- Whenever possible an engineering metaphor would be used in the games.

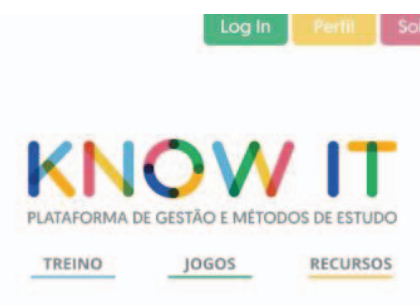

Fig. 1 LearnIt (Know It) Interface 
The design process of each mini-game was then connected to the following points:

- Identify common games for a specific cognitive area. Assess if they were fitted for the target group and if it was possible to wrap them in an engineering metaphor and, if so, adapt them;

- Design new games for cognitive areas lacking enough games or were new, focused, games would contribute more to the objective;

- Connect the games to the repository of learning contents.

The player's motivation was also a relevant aspect considered in the design of the application, following the justification provided in the previous section. Flow was addressed by creating different mechanisms like levels, scores and rankings, therefore adjusting the challenges difficulty to the player's ability.

The mini-games are the main focus of the application. All games evaluate the user's performance through a system of points. For every correct answer the player receives a number of points that varies depending on the estimated time needed to reach the answer.

For any mini-game, the player aims to achieve a minimum of 500 points in a 60 second-time limit. This means that some mini-games consist of several rounds. In these, each round also has its own time limit, always less than 60 seconds. If the player cannot solve the rounds in that time, it is deemed to have failed the round and a new one is generated.

Next, the objectives and rules of the most relevant minigames are presented:

\section{Memory area}

- Cards: In this mini-game, two decks of cards are presented face down on the screen, one on left and one on the right. Each card has a symbol that differs in colour and shape. The symbol from the right deck is revealed for a few seconds and is then inserted in the left deck, face down. Then a new symbol from the right deck is revealed and remains visible waiting for the response from the user. The player must then indicate whether the symbol drawn on the second card is equal to or different from the first symbol displayed. After answering, the symbol revealed in the right deck is turned down and inserted in the left deck. A new card is revealed in the right deck and the process is repeated until the time is over. As the difficulty increases, so does the number of cards face down. For example, in the intermediate difficulty level the player must indicate whether the symbol in the card is the same or different from the symbol on the penultimate letter.

- Trademarks and logos: Logos and brands of companies and products are shown to the player, along with their name written underneath. They are on the screen for a few seconds before being shuffled and the logos partially covered. Then the player is asked to correctly make the connection between the modified logos and the names. The player must match all correctly to be awarded points. Afterwards new logos and names are generated, starting a new phase of challenges for the user to respond. In the higher levels the number of matches that the player has to do in each round increases.

- Pairs: a grid is presented with several cards face down. Each card has a symbol, and there are only two cards with the same symbol. The player must find the matching pairs of symbols, selecting two cards at a time. When choosing a card, it turns up. If the player can find two cards with the same symbol, both remain face up. If it fails, the two cards selected are again face down, thus hiding their symbol. The player must then resort to memory to successfully find all pairs in the grid before time runs out. At higher difficulty levels, the grid is larger, with more pairs of symbols. Also, during the game the grid randomly turns in $90^{\circ}$ angles, forcing the player to adapt his memory of the cards position to a new layout.

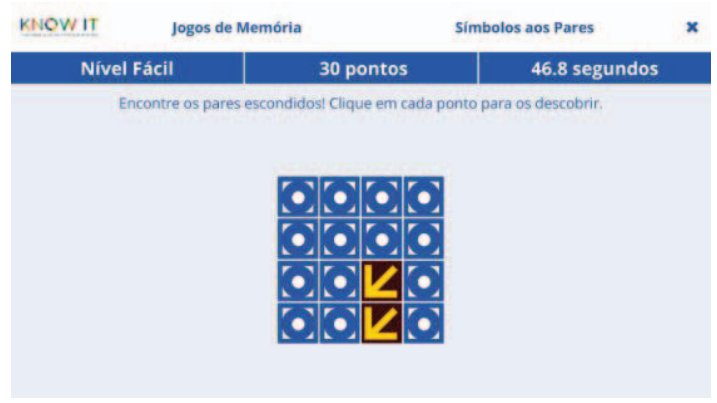

Fig. 2 Pairs mini-game

\section{Verbal reasoning area}

- Word search: Based on the traditional game of alphabet soup a grid is presented with several apparently random letters. On the right side of the playing area, there are word definitions. The game goal is to find the words in the soup of letters that correspond to the given definitions. Words can be represented vertically or horizontally in any direction. In the most difficult levels, the grid size and the number of words to find increase.

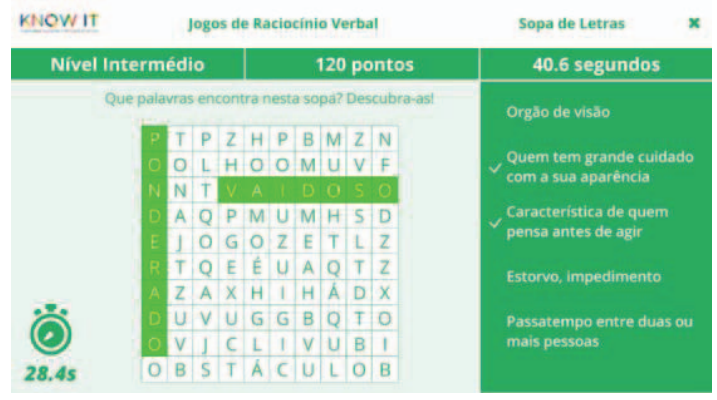

Fig. 3 Word search mini-game

- Synonyms and antonyms: At the top of the screen a list of words is displayed. At the bottom of the playing area there are various boxes with words. These words correspond to synonyms or antonyms of the words at the top of the screen. The player must then connect the words of the top of the screen with the correct box. It is not disclosed to the user if the word must match a synonym or an antonym. The player depends only on his knowledge of the language to complete the challenge. At 
higher levels, the number of matches that the player has to do in each round increases.

- Loose syllables: In this game, words are divided in syllables. Syllables emerge from the top of the screen, falling to the green edge of the bottom of the playing area. When they reach the edge, the syllables destroy themselves and it is no longer possible to interact with them. The player's goal is to select the syllables that make up a word before it is destroyed. The fragments should be selected in the correct order to form the word. For example, the word "computer" will be divided into parts "com", "pu" and "ter". With increasing difficulty, the complexity of words also increases.

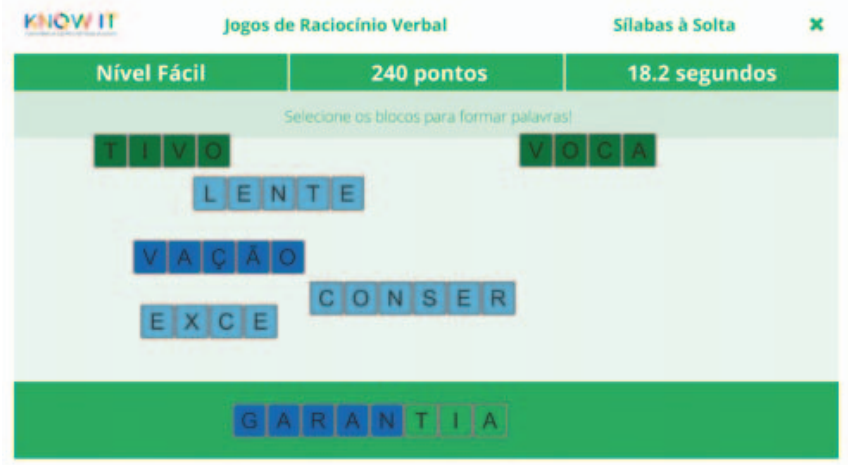

Fig. 4. Loose syllables game

\section{Numerical reasoning area}

- Math bubbles: Bubbles appear on the screen, falling to the bottom of the playing area. Within the bubbles are simple mathematical expressions that must be solved. In the right part of the screen is a numeric keyboard. The player's goal is to solve the mathematical accounts in the order they appear, as soon as possible. To this end, he/she may use the keyboard that appears on the screen or can use the physical keyboard. As the difficulty level increases, the complexity of the expression that must be solved also increases.

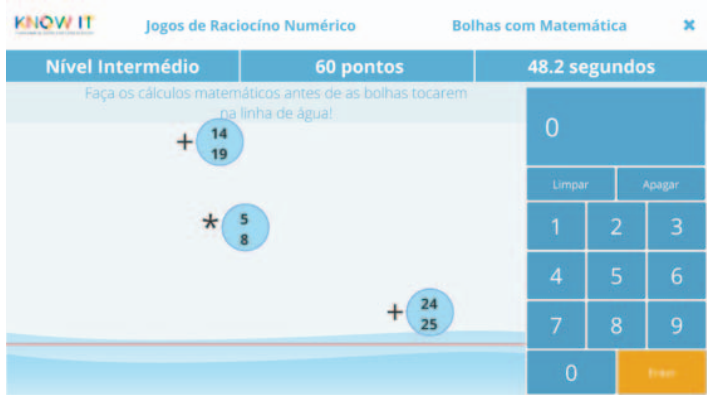

Fig. 5 Bubble math mini-game

- Prices and discounts: various products are presented along with their normal price. Beside each product is a sticker with a discount percentage that has been applied to the product (the shown price does not include the discount). The player must select the products in order, from the cheaper to the more expensive, calculating the final price. Afterwards the game generates a new set of products with different prices and discounts. The process is repeated until the time is ended. In higher levels, the final prices become more difficult to calculate. The number of products displayed in a single round also increases.

- Spin stick: In this game a stick is surrounded by small balls. The user can rotate the stick to the left and right using the arrow keys or the arrow-shaped buttons on the screen. The goal is to separate the balls into two groups containing the same number of balls in each. The player must repeat the process until the time reaches the end. As a single right answer does not give enough points to meet the goal, the player has to decide how to count and also split the balls on the screen as soon as possible. As soon as the difficulty goes up, the number of balls also increases.

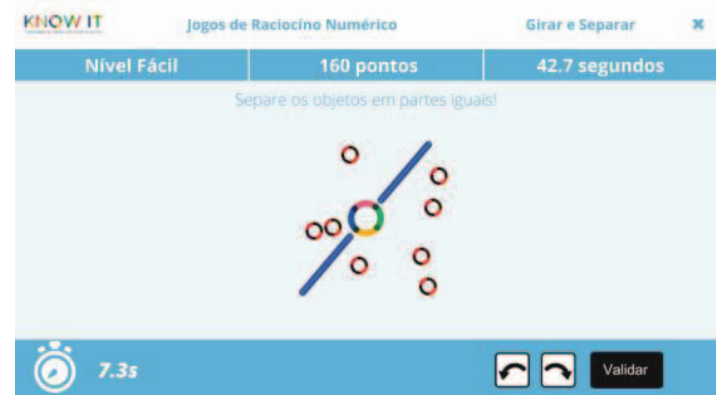

Fig. 6 Spin stick mini-game

\section{Abstract reasoning area}

- Logical sequences: At the top of the playing area, three images that follow a logical sequence are presented. Below are 6 similar images, however, only one of them is the correct continuation of the logical sequence presented above. The player must select the correct answer among the 6 possible. For each round the user only has an opportunity to respond. Higher difficulty levels mean greater complexity in the logical sequences.

- 3D plan: The user is shown a cube with different patterns on each side. On the right side of the screen are five different flat patterns cubes. It is for the player to select the flat representation that matches the presented cube. Once answered, a new challenge is generated with a new cube and new flat patterns to choose from. With increasing difficulty increases the complexity of the patterns on the cube faces.

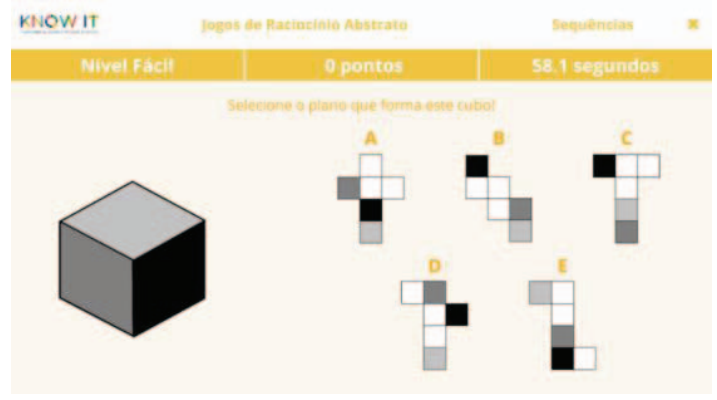

Fig. 7 3D plan mini-game

- Tangram: Inspired by the classic tangram, in this game several pieces of different polygonal shapes are presented in the right corner of the screen. In the centre of the play area there is a pattern where the pieces fit. In addition to dragging the pieces to the right place in the pattern, the user can also rotate them. In some puzzles, it 
is really essential to do so to have a correct fit. The goal is then to use the pieces to form the pattern shown in the centre. The player has only 20 seconds to assemble all the pieces in the presented figure, so he/she has to think quickly on how and where to place the tangram pieces. After graduating successfully figuring it out (or after 20 seconds) the game advances to the next round with a new figure and a new set of parts. On higher difficulty levels, the complexity of the form increases, as well as the number of pieces of tangram necessary to form it.

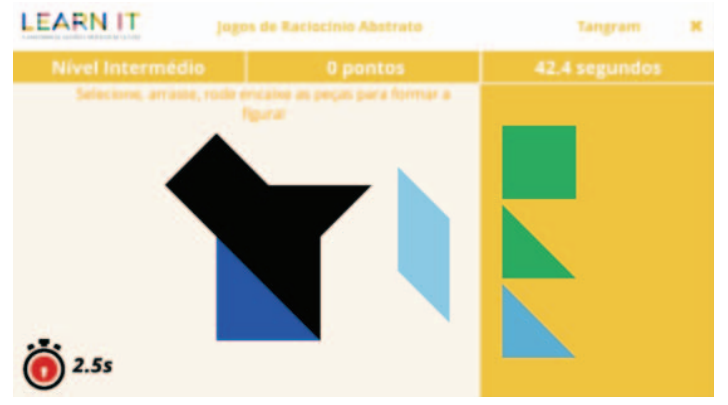

Fig. 8 Tangram mini-game

\section{Concentration and attention area}

- Moving fish: In this mini game emerge from 2 to 4 different colour shoals of fish. The shoals appear randomly in any of the four sides of the play area, always moving towards the opposite side. The player must indicate to which direction fishes of a particular colour are moving. For this, they can use the arrow keys on the physical keyboard or the buttons available at the bottom of the screen. After answering, the shoals disappear and the game generates a new set of shoals with new colours, and fishes swimming in other directions. With increasing difficulty increases the number of generated shoals. At the highest difficulty level, the game generates a different fish from all the others. The player has to find this fish and identify to which direction it points. Since this is a single fish in shoals of several means, it is hardly noticeable.

- Boats and ferries: The playing area consists of a simple map with ports and ferries of different colours. The goal is to make the boats arrive correctly to the port with the same colour. Boat paths have intersections and in each there is an arrow pointing to one of the possible routes. When they come to an intersection, the boats follow the route indicated by the arrow. The player can click or touch the arrows to change which way point, thus influencing the itinerary of any boat that comes into contact with the crossings. The user must constantly adjust the direction of the arrow keys to drive the boats to the right port. Three maps were created, one for each level of difficulty. The amount of ports, ferries and roads increases in the higher levels.

- Pulley: In the centre of the screen a circle is displayed with other circles connected by a straight line as if they were needles stuck in the object. The centre circle is turning, causing the bound circles to follow the movement. In the bottom of the screen is a button with the word "Shoot" and a small circle slightly above the button. The purpose of the mini-game is to shoot new needles to the central object, without hitting the needles already connected to the object. At the bottom left is the number of shots available to do it correctly. If the user fails, he/she must restart the round until he/she hits all the required shots. After completion of the round, a new circle is generated, but with a number and positioning of needles different. In each round can also vary the number of shots the player must hit.

\section{Emotions area}

- Guess who: several photographs of people with varying facial expressions are displayed. At the bottom left is a statement that tells which emotion the player must identify: joy, sadness, surprise, etc. The player has a few seconds to indicate correctly all the pictures that match the requested emotion. It is mandatory to choose only the photos that match that emotion and not miss one. Selecting an image that corresponds to any other emotion, or ignoring one or more images that match the correct emotion causes the player to lose the round. As the difficulty increases, more and more pictures per round on the screen are presented with the same time limit.

- Emoticons: At the top of the screen, a set of pictures of people with different facial expressions is shown. At the bottom of the playing area, there is an equal number of emoji's representing the same emotions as the photos. Among these two groups of images there are obstacles in the form of pulleys and traps moving across the screen. The aim is to link the emoji and images with the same emotion, avoiding the obstacles placed between them. The player selects an emoticon, using the mouse or by touching the screen, and dragging it to the correct picture. At higher difficulty levels, the number of pictures and emojis increase.

At any moment, the user has access to a complete profile, identifying his/her scores in each area, therefore indicating which areas must be worked more. The user profile can be kept offline if the user just intends to use a single device or can be available online allowing the user to login in different devices.

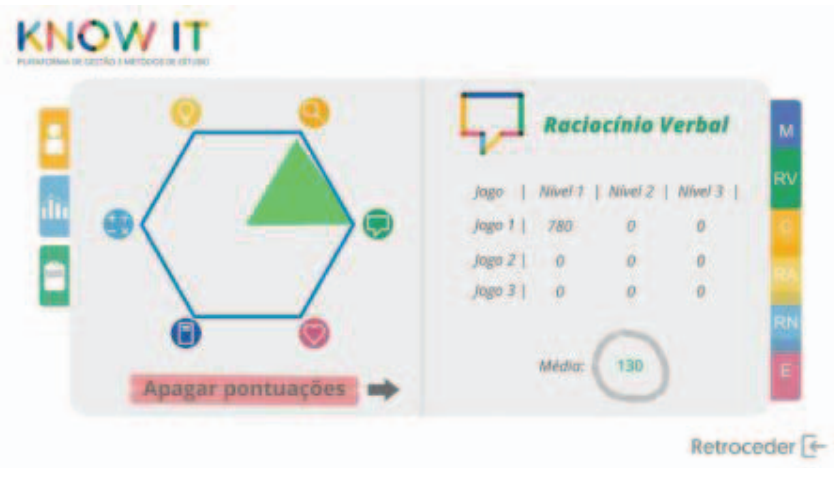

Fig. 9 User profile

The application includes a contextualized repository of learning resources that can be suggested to the user according to his/her profile. These resources are related to the study methods and also to the cognitive domains and several heuristics are used to connect the obtained scores to the relevant resources. Nevertheless, the users can freely browse the complete list of resources. 
A different application was created to manage the repository of learning resources and their relation to the study methods and cognitive domains.

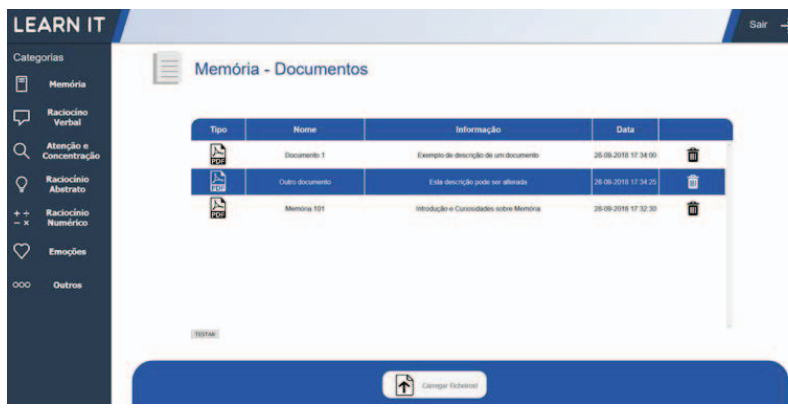

Fig. 10 Learning resource management

The game was developed in Unity 3D [17] and is currently available for Windows, MacOs, iOS and Android. Although specifically designed for engineering students (in terms of challenges), it can, in fact, be used by anyone.

\section{RESULTS}

The evaluation of the LearnIt was carried out by two different groups of Engineering students. Students were given a brief introduction to the game and then they were able to download the game and play with it freely. After two weeks, students answered a questionnaire designed to gather their opinions and perceptions on three different dimensions: usability, gameplay and cognitive development. The questionnaire was formed by a set of closed questions with a Likert scale (from 1 - fully disagree to 5 - fully agree), and an open question. In total, 28 students completed the game evaluation. Next, we present the most relevant results obtained in this assessment. Table 2 refers to usability.

Table 2. Usability assessment

\begin{tabular}{|c|c|c|c|c|c|c|}
\hline & \multicolumn{6}{|c|}{ \#answers } \\
\hline & 1 & 2 & 3 & 4 & 5 & NR \\
\hline The interface is intuitive & 0 & 0 & 1 & 10 & 17 & 0 \\
\hline The interface is simple & 0 & 1 & 1 & 10 & 16 & 0 \\
\hline The interface is quick to respond & 1 & 0 & 4 & 8 & 15 & 0 \\
\hline $\begin{array}{c}\text { The application design is } \\
\text { homogeneous }\end{array}$ & 0 & 0 & 3 & 12 & 13 & 0 \\
\hline $\begin{array}{c}\text { Ifelt in control while navigating } \\
\text { through the screens }\end{array}$ & 0 & 2 & 6 & 9 & 12 & 0 \\
\hline $\begin{array}{c}\text { It is easy to access the game } \\
\text { features }\end{array}$ & 0 & 0 & 2 & 14 & 12 & 0 \\
\hline The information presented is clear & 0 & 2 & 3 & 14 & 9 & 0 \\
\hline $\begin{array}{c}\text { The information presented is well } \\
\text { written }\end{array}$ & 0 & 0 & 3 & 11 & 14 & 0 \\
\hline
\end{tabular}

The information presented is useful

The graphics are good

\begin{tabular}{|l|l|l|l|l|l|}
\hline 0 & 0 & 5 & 13 & 10 & 0 \\
\hline 0 & 1 & 5 & 13 & 9 & 0 \\
\hline
\end{tabular}

The usability assessment was quite positive with average value of answers ranging from 4.1 to 4.6. Some improvement is necessary concerning the presented information, though. On the other hand, the most positive aspects relate to the intuitiveness of the interface, its simplicity and the quick response time.

Table 3. Gameplay assessment

\begin{tabular}{|c|c|c|c|c|c|c|}
\hline \multirow{2}{*}{ questions } & \multicolumn{6}{|c|}{ \#answers } \\
\hline & 1 & 2 & 3 & 4 & 5 & NR \\
\hline $\begin{array}{l}\text { The controls are appropriate } \\
\text { for the mini-games }\end{array}$ & 0 & 0 & 4 & 8 & 16 & 0 \\
\hline $\begin{array}{c}\text { The difficulty of games is } \\
\text { adequate }\end{array}$ & 2 & 7 & 15 & 4 & 0 & 0 \\
\hline The games are fun to play & 1 & 2 & 14 & 8 & 3 & 0 \\
\hline The games cause frustration & 8 & 8 & 7 & 2 & 3 & 0 \\
\hline
\end{tabular}

Scores in the gameplay assessment were, in general, lower than in the usability variable. Extra work is therefore required to improve the game, namely referring to difficulty and fun. Nevertheless, the controls were considered quite adequate and the flow level was considered correctly dimensioned.

Table 3. Cognitive development assessment

\begin{tabular}{|c|c|c|c|c|c|c|}
\hline \multirow{2}{*}{ questions } & \multicolumn{6}{|c|}{ \#answers } \\
\hline & 1 & 2 & 3 & 4 & 5 & NR \\
\hline $\begin{array}{l}\text { I can learn something from this } \\
\text { application }\end{array}$ & 0 & 4 & 8 & 12 & 4 & 0 \\
\hline $\begin{array}{c}\text { When using this application, I felt that } \\
\text { my results have improved }\end{array}$ & 1 & 2 & 12 & 10 & 3 & 0 \\
\hline $\begin{array}{l}\text { The application can be useful to } \\
\text { improve my cognitive skills }\end{array}$ & 1 & 1 & 12 & 9 & 5 & 0 \\
\hline $\begin{array}{l}\text { The application can be useful to } \\
\text { improve my study methods }\end{array}$ & 4 & 5 & 12 & 4 & 3 & 0 \\
\hline
\end{tabular}

The perception of the participants regarding the cognitive development was positive but some aspects must be reinforced. This might also be resulting from inadequate perceptions of the user in relation to their own cognitive abilities. 
As a final question, participants were asked about their favourite games. Clearly, the preference went to numeric reasoning games, namely the math bubbles. The first game related to the emotions area was also appreciated.

\section{Table 5. Game preference}

\begin{tabular}{|c|c|c|c|c|c|c|c|c|}
\hline \multicolumn{3}{|c|}{ Memory } & \multicolumn{3}{|c|}{ Verbal reasoning } & \multicolumn{3}{|c|}{$\begin{array}{c}\text { Concentration and } \\
\text { attention }\end{array}$} \\
\hline $\begin{array}{c}\text { game } \\
1\end{array}$ & $\begin{array}{l}\text { game } \\
2\end{array}$ & $\begin{array}{c}\text { game } \\
3\end{array}$ & $\begin{array}{c}\text { game } \\
1\end{array}$ & $\begin{array}{c}\text { game } \\
2\end{array}$ & $\begin{array}{c}\text { game } \\
3\end{array}$ & $\begin{array}{c}\text { game } \\
1\end{array}$ & $\begin{array}{c}\text { game } \\
2\end{array}$ & $\begin{array}{c}\text { game } \\
3\end{array}$ \\
\hline 5 & 10 & 3 & 5 & 6 & 3 & 4 & 6 & 9 \\
\hline \multicolumn{3}{|c|}{ Abstract reasoning } & \multicolumn{3}{|c|}{ Numerical reasoning } & \multicolumn{3}{|c|}{ emotions } \\
\hline $\begin{array}{c}\text { game } \\
1\end{array}$ & $\begin{array}{c}\text { game } \\
2\end{array}$ & $\begin{array}{c}\text { game } \\
3\end{array}$ & $\begin{array}{c}\text { game } \\
1\end{array}$ & $\begin{array}{c}\text { game } \\
2\end{array}$ & $\begin{array}{c}\text { game } \\
3\end{array}$ & $\begin{array}{c}\operatorname{gam} \\
1\end{array}$ & $\begin{array}{c}\text { gam } \\
2\end{array}$ & \\
\hline 5 & 8 & 1 & 12 & 4 & 4 & 11 & 4 & \\
\hline
\end{tabular}

Summarizing the obtained results, we can state that LearnIt was a success in several aspects: there was a considerable number of users who considered the application fun, intuitive, well designed and with a very consistent appearance. The variety of available mini-games was a highly praised feature, which shows that the app can appeal to users with different tastes. The difficulty levels and the progression scheme was also seen as a positive aspect, believed to be well balanced and fair. In addition, more than half of the participants stated that they felt having developed some cognitive functions by using the game.

Nevertheless, only a few users mentioned they had used the game on a daily basis. Because the regular use of the application is one of the most important aspects of its operation, this feedback indicates that adjustments must be made in the motivating factors of the game.

\section{CONCLUSIONS}

This work results from the identification of gaps within students' organization and study methods, which directly impact not only their academic success, but also on the development of their cognitive competences. The purpose of this work was then to create a motivational tool that allowed Engineering students to better apply some study methods by improving some cognitive functions. For that purpose, a serious game was designed, developed and validated. The evaluation of the game, done with students from an Engineering Faculty, was focused on the assessment of its usability, gameplay and cognitive development. By doing that it was also possible to assess the level of motivation and fun that students experience when playing the game.

Regarding these two last aspects, the results of the evaluation were, in general, positive, with most users agreeing that the app provides fun and that it can motivate for its continuous use towards cognitive development. Most users were also satisfied with the quality of the software and its easy-to-use interface. There was dispersion in the identification of the most fun mini-games which indicates that LearnIt can cater for different personal tastes. Yet, a large number of students did not see the game as something they would want to use daily, so this aspect must be improved.

We are fully aware that to be able to ascertain improvements in cognitive functions would require a completely different validation approach. Although the project was supported by a group of psychologists, they are experienced in supporting the students rather than with research in the cognitive domain. Therefore, a new stage of the project is now starting with the inclusion of neuroscientists from the Medical Faculty to completely design a more extended validation process using neurological tools which will certainly provide more accurate results concerning the impact in the cognitive functions.

\section{REFERENCES}

[1] JM Gambill, LA Moss, and CD Vescogni, "The impact of study skills and organizational methods on student achievement", [online] Available at: https://files.eric.ed.gov/fulltext/ED501312.pdf [Accessed 17 January 2018].

[2] N Mutsotso, S \& Elizabeth, Abenga., "Study methods for improving quality learning and performance in higher education". Educational Research and Reviews. 5. 2010 [Accessed 17 January 2018].

[3] SOAR, "Developing Effective Study Habits", [Online] Available at : http://www2.gcc.edu/arc/docs/StudyTips1.pdf,

[4] K. Lonka, \& K. Ahola, "Activating instruction: How to foster study and thinking skills in higher education", European Journal Psychology Education, 10: 351, 1995

[5] C. Abt, Serious Games, University of California: Viking Press, 1970.

[6] K. Salen, E. Zimmerman, Rules of Play: Game design fundamentals. MIT Press, 2004.

[7] D Gouveia, D Lopes and CV De Carvalho, "Serious gaming for experiential learning", Frontiers in Education Conference (FIE), 2011, T2G-1-T2G-6.

[8] CV de Carvalho, "Is game-based learning suitable for engineering education?", Global Engineering Education Conference (EDUCON), 2012 IEEE, pp. 1-8.

[9] S. Chen \& D. Michael. Serious Games: Games that Educate, Train and Inform. USA, Thomson Course Technology, 2005

[10] M. Zyda, "From visual simulation to virtual reality to games". IEEE Computer, 2005

[11] V. Wattanasoontorn, I. Boada, R. Garcia and M. Sbert, "Serious games for health". Entertainment Computing, December, 4 (4), pp. 231-247, 2013.

[12] CV de Carvalho, MP Lopes and AG Ramos, "Lean games approaches-simulation games and digital serious games", International Journal of Advanced Corporate Learning (iJAC) 7 (1), pp. 11-16.

[13] M. Csikszentmihalyi, Flow: The Psychology of optimal experience. Harper Collins.

[14] S. Baron, "Gamasutra". [Online] Available at: https://www.gamasutra.com/view/feature/166972/cognitive flow the psychology of .php [Accessed 23 February 2018].

[15] D. Bavelier and R. Davidson, "Brain training: Games to do you good.", Nature. 494. 425-6. 10.1038/494425a., 2013.

[16] Federal Trade Commission, "Lumosity to Pay \$2 Million to Settle FTC Deceptive Advertising Charges for Its "Brain Training" Program", [Online] Available at https://www.ftc.gov/newsevents/press-releases/2016/01/lumosity-pay-2-million-settle-ftcdeceptive-advertising-charges, [Accessed 23 February 2018].

[17] R. Nouchi, Y. Taki, H. Takeuchi, H. Hashizume, T. Nozawa, T. Kambara, A. Sekiguchi, CM Miyauchi, Y. Kotozaki, H. Nouchi, R. Kawashima. "Brain Training Game Boosts Executive Functions, Working Memory and Processing Speed in the Young Adults: A Randomized Controlled Trial". PloS one. 8. e55518. 10.1371/journal.pone.0055518, 2013.

[18] J. Torrente, A. Blanco, P. Moreno-Ger, \& B. Fernandez-Manjon, "Designing serious games for adult students with cognitive 
disabilities". In Tingwen Huang, Zhigang Zeng, Chuandong Li, and ChiSing Leung, editors, Neural Information Processing, volume 7666 of Lecture Notes in Computer Science, pages 603-610. Springer Berlin Heidelberg, 2012.

[19] CS. Lanyi \& David Joseph Brown. "Design of serious games for students with intellectual disability". 2010 International Conference on Interaction Design \& International Development, pages 44-54. British Computer Society, 2010.

[20] A.M. Hussaan, K. Sehaba, and A. Mille. "Tailoring serious games with adaptive pedagogical scenarios: A serious game for persons with cognitive disabilities". 11th IEEE International Conference on Advanced Learning Technologies (ICALT), pages 486-490, 2011.

[21] C.S. Lanyi, D.J. Brown, P. Standen, J. Lewis, V. Butkute, and D. Drozdik. "European project of serious games for students with intellectual disability". In 2nd International Conference on Cognitive Infocommunications (CogInfoCom), pages 1-6, 2011.
[22] Nintendo, "Brain Age", [Online] Available http://brainage.nintendo.com/ [Accessed 23 February 2018].

[23] R. Kawashima, "Train Your Brain: 60 Days to a Better Brain", Penguin Books, 2005. [Accessed 23 February 2018].

[24] Lumos Labs, "Lumosity", [Online] Available at: https://www.lumosity.com/ [Accessed 23 February 2018].

[25] Peak, "Peak". [ Online] Available at: http://www.peak.net/ [Accessed 23 February 2018].

[26] BrainGymmer, "BrainGymmer", [Online] Available at: https://www.braingymmer.com/ [Accessed 23 February 2018].

[27] Fit Brains, "Fit Brains", [Online] Available at: http://www.fitbrains.com/ [Accessed 23 February 2018].

[28] Unity Technologies, 2017. "Unity User Manual (5.6)", [Online] Available https://docs.unity3d.com/560/Documentation/Manual/index.html [Accessed 23 February 2018] 